\title{
Soil Resistivity: A Limiting Determinant to Zero-Sequence Currents for Grounded Conductors in South African Low Voltage Networks
}

\author{
Q. Louw and P. Bokoro \\ Department of Electrical and Electronic Engineering Technology \\ University of Johannesburg \\ Doornfontein Campus - Doornfontein, 2028 Johannesburg (South Africa) \\ Phone/Fax number: +0027 559 6114, e-mail: 809088334@student.uj.ac.za,pitshoub@uj.ac.za
}

\begin{abstract}
In this paper, the dependence of soil resistivity on the geological structure and meteorological conditions are discussed. The South African context of changing resistivity and its inevitable consequences on the behaviour of prospective zerosequence currents in low-voltage distribution systems is highlighted. Therefore, field measurements of soil resistivity using the Wenner Array technique is conducted on expansive clay-based soil. The resulting zero-sequence current inherent to the soil conditions is also assessed. The results obtained indicated that the soil resistivity value of $488.74 \Omega$. m, which corresponds to the soil conditions at the time and measurement season, represents an increase of $62.91 \%$ of the standard limit value for expansive clays, and causes $37.14 \%$ decrease in the zerosequence current likely to flow at the limit value of expansive clay's resistivity.
\end{abstract}

\section{Key words}

Soil resistivity, zero-sequence current, grounded conductor, soil resistance.

\section{Introduction}

According to the World Bank sustainable energy statistics, access to electricity in the African continent is estimated to be $23 \%$ to $82.2 \%$ [1]. Recently published statistics indicated that South Africa access to electricity has climbed to $90.3 \%$ [2]. The reported rise in electricity access could possibly be attributed to rural electrification rollout program, which is aimed at providing grid electricity to thousands of rural dwellings and other installations within shortest timeframe possible. As a result of this key deliverable, a strategy is adopted to deploy an overhead conductor system using poles, distribution transformers and in the majority of the cases overhead low voltage conductor to supply the households. However, this form of supply commonly provides an opportunity for ground faults to occur as a result of fallen or broken live conductors. For the purpose of this paper, the effect of soil resistivity on zero-sequence impedance is evaluated. Therefore, on-field resistivity tests are conducted on typical South African soil conditions using the wenner array method. The measurements obtained as well as typical low-voltage (LV) transformer specifications are used to estimate the magnitude of zero-sequence currents under different soil conditions. The results obtained indicate that the soil type and conditions in which an earth fault may be developed is an important limiting deterministic factor to the overall zero-sequence impedance.

\section{Network Topology}

In the context of South African rural electrification, the typical LV distribution network consists of cement poles, 3 -phase distribution transformers ranging from $100 \mathrm{kVA}$ to $315 \mathrm{kVA}$ and overhead conductors (3-phase and 1 neutral). The service connection to consumers is achieved with the aid of a single-phase AIRDAC cable. The standard LV distribution network is depicted in figure 1.

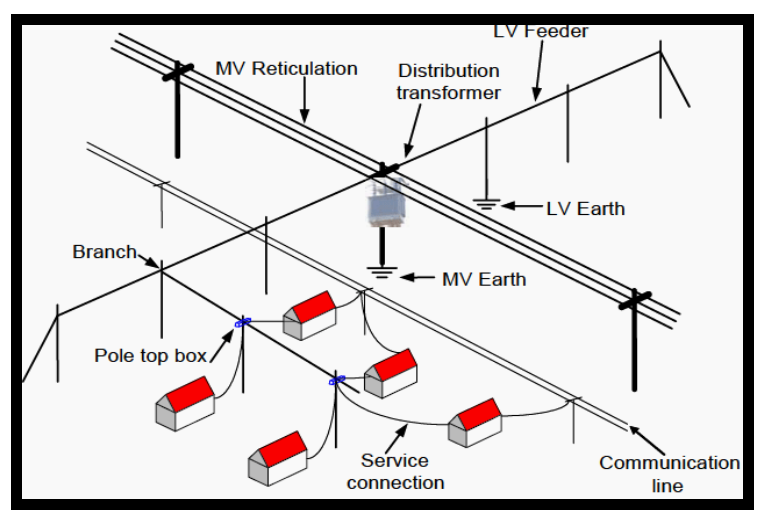

Fig. 1. Typical LV Network Topology.

In accordance with the South African National Standards (SANS) 10292 [3] as well as the International Electrotechnical Commission (IEC) 60364-1:2005 [4], the LV distribution feeder consists of TN-C-S system. It is worth noting that single earthing solution at the low voltage side of the transformer is adopted in South African LV distribution systems. This implies that the low voltage side of the transformer neutral and earth are terminated on the N-busing of the power transformer. Therefore, the system is effectively earthed and makes no provision for intentional series resistance along the earthing circuitry, and thus the earth terminal or conductor forms the main path for zero-sequence currents 
to be returned back to the distribution transformer. This configuration is indicated in figure 2 .

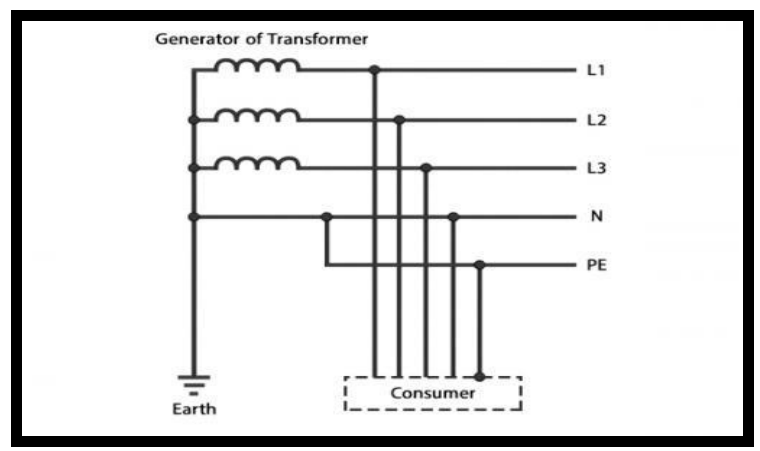

Fig. 2. TN-C-S LV System.

\section{Expansive Clay Soil Resistivity}

Soil resistivity plays an important role in the determination of ground fault or zero-sequence current magnitude. The IEEE Std. 81-2012 [5] defines soil resistivity ( $\rho$-Rho) as the measurement of the soil volume required to experience significant resistance to current flowing through. Kizhlo et al [6] reported on the misconception usually perpetrated between resistivity and resistance. These electrical quantities, although interrelated, refer to important and distinct electrical parameters. Ground resistance refers to the relationship between the grounding electrode and the soil environment and forms integral part of the earth fault current impedance path. Ground resistance is directly influenced by the condition of the soil. Whereas, resistivity which is also referred to as specific resistance, may be defined as the resistive property experienced or measured between two opposite sides of one square-metres area of soil. The parameters affecting soil resistivity are mainly related to geological and environmental conditions such as: soil composition, temperature, moisture, etc. In theoretical terms the soil resistivity should not change in a homogenous isotropic environment. However, in practical terms the conditions are non-homogenous due to various layers of the soil which include layers of the top soil, subsoil and rock [7]. The resistivity and ground resistance are directly affected by seasonal (meteorology) changes, and more specifically by the moisture content of the soil. These changes tend to influence the nature of through-ground conduction phenomenon. In the South African context, the most commonly found type of soil in rural areas happens to be a mixture of silica sand and expansive clay with silica sand consisting of the top layer [8]. The distribution of expansive clay is shown in figure 3 .

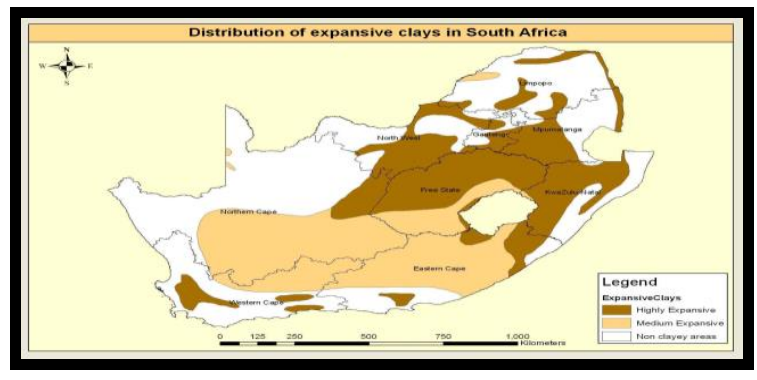

Fig. 3. Distribution of expansive clays in South Africa [8].
Clay particles of expansive clay-based soil are able to attract and retain moisture molecules between the clay crystals. Moisture content and atmospheric temperature consist of major regulating factors of the swelling and shrinking phenomena of expansive clay soil. These phenomena tend to influence the electrical resistivity of the soil. Therefore, low temperature seasons cause water molecules to be pulled further down in the soil structure and thus resulting in increased soil resistivity. In high temperature periods, the ground appears to be very dry as a result of evaporation. Under this condition, the soil resistivity is reduced. This is indicated in figure 4 .

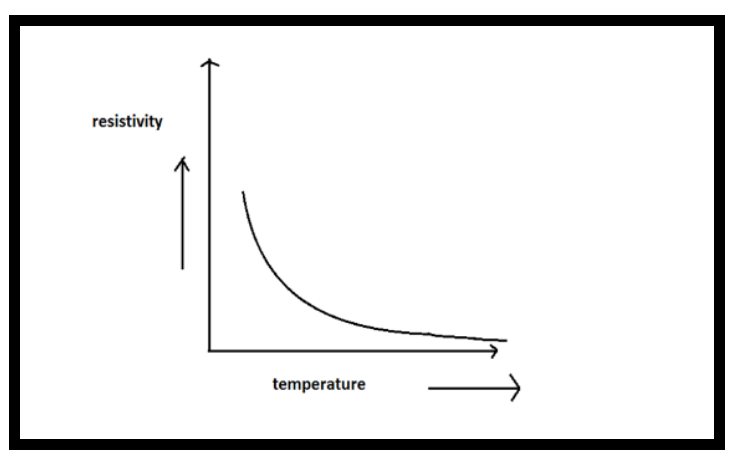

Fig. 4. Resistivity versus Temperature Curve [9].

The typical resistivity values for several types of soil and water are recorded in Table I [9].

Table I. - Typical values of soil resistivity

\begin{tabular}{|c|c|c|}
\hline $\begin{array}{c}\text { Types of } \\
\text { Soil/Water }\end{array}$ & $\begin{array}{c}\text { Typical } \\
\text { Resistivity }(\Omega . \mathrm{m})\end{array}$ & $\begin{array}{c}\text { Usual Limit } \\
(\Omega . \mathrm{m})\end{array}$ \\
\hline Sea Water & 2 & $0.1-10$ \\
\hline Clay & 40 & $8-70$ \\
\hline $\begin{array}{c}\text { Ground Well and } \\
\text { Spring Water }\end{array}$ & 50 & $10-150$ \\
\hline $\begin{array}{c}\text { Clay and Sand } \\
\text { mixtures }\end{array}$ & 100 & $4-300$ \\
\hline $\begin{array}{c}\text { Shale, slates and } \\
\text { Sandstone }\end{array}$ & 120 & $5-250$ \\
\hline $\begin{array}{c}\text { Peat, Loam and } \\
\text { Mud }\end{array}$ & 150 & $100-400$ \\
\hline $\begin{array}{c}\text { Lake and Brook } \\
\text { Water }\end{array}$ & 250 & $200-3000$ \\
\hline Sand & 2000 & $4-10000$ \\
\hline Moraine gravel & 3000 & $10000-50000$ \\
\hline Ridge gravel & 15000 & $10000-100000$ \\
\hline Solid granite & 25000 & \\
\hline Ice & 100000 & \\
\hline
\end{tabular}

\section{Field Testing Methodology}

Field testing of soil resistivity can be accomplished using various techniques: the Wenner Array, the Schlumberger Array and the Fall of Potential methods. For the purpose of this paper, the Wenner Array method is used. Although this technique requires high operational demand due to the fact that a larger cross-sectional area is tested, however it is known to be the most efficient in terms of producing tangible data. The Wenner Array 
method involves spacing four electrodes in the ground at equal distances, which should be larger than 1 metre. A current source is connected between the two outer electrodes with voltage measurements being taken between the two inner electrodes. The electrodes are then moved around in different configurations and an apparent resistivity is measured as a result of change in voltage $(\Delta \mathrm{V})$. The test set up is shown in figure 5.

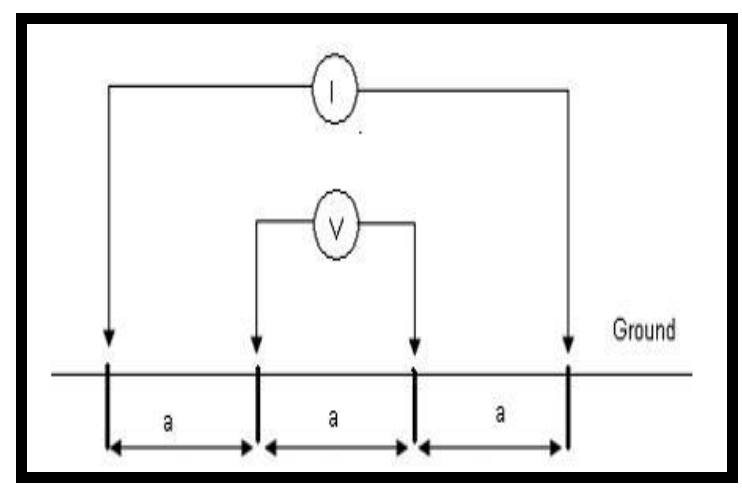

Fig. 5. Wenner Test Set up [10].

The traverse test result is a value of the apparent resistivity for the various configurations and spacing [10].

$$
\rho=2 \pi \mathrm{a} \cdot\left(\frac{\Delta \mathrm{V}}{\mathrm{I}}\right)
$$

Where:

$\rho \quad$ : is the apparent resistivity in ohm-metres $(\Omega-\mathrm{m})$;

a $\quad$ is the probe spacing in metres $(\mathrm{m})$;

$\Delta \mathrm{V}:$ is the applied voltage in volts $(\mathrm{V})$;

I : is the injected current in Amperes (A);

$\mathrm{R} \quad$ : is the resistance in ohms $(\Omega)$.

For the purpose of this test, the Chauvin Arnoux model 4630 test unit was used. This unit performs 15 seconds automatic ranging to determine the soil resistance by injecting a maximum current of $10 \mathrm{~mA}$ through the outermost electrodes. The spacing between the electrodes was kept as equal as possible at 3.05 metres and at a ground depth of $15 \mathrm{~mm}$. The voltage reading across the inner electrodes did not exceed 42 V. Similarly, the RS Pro RS52 two-input digital thermometer was used to determine the soil temperature. The thermometer probes were driven to the soil at the same depth with the test electrodes.

\section{Influence of Soil Resistivity on Zero- Sequence Current}

Low Voltage networks such as defined in the South African context are typically a 3-phase, 4- wire system. The statutory low voltage arrangement in these networks is $415 \mathrm{~V}$ phase to phase and $240 \mathrm{~V}$ phase to neutral. The supply source to each consumer consists of standard 3phase distribution transformer with the following ratings: $100-315 \mathrm{kVA}$ at $11 / 0.415 \mathrm{kV}$ with $4 \%$ impedance and effectively earthed at the star point. Therefore, protection practice requires earth fault or zero-sequence currents occurring in such distribution networks are returned to the source through ground conductors. This implies that moisture content and temperature dictates the level or magnitude of zero-sequence currents. The influence of soil resistance on zero-sequence current is demonstrated in figure 6.

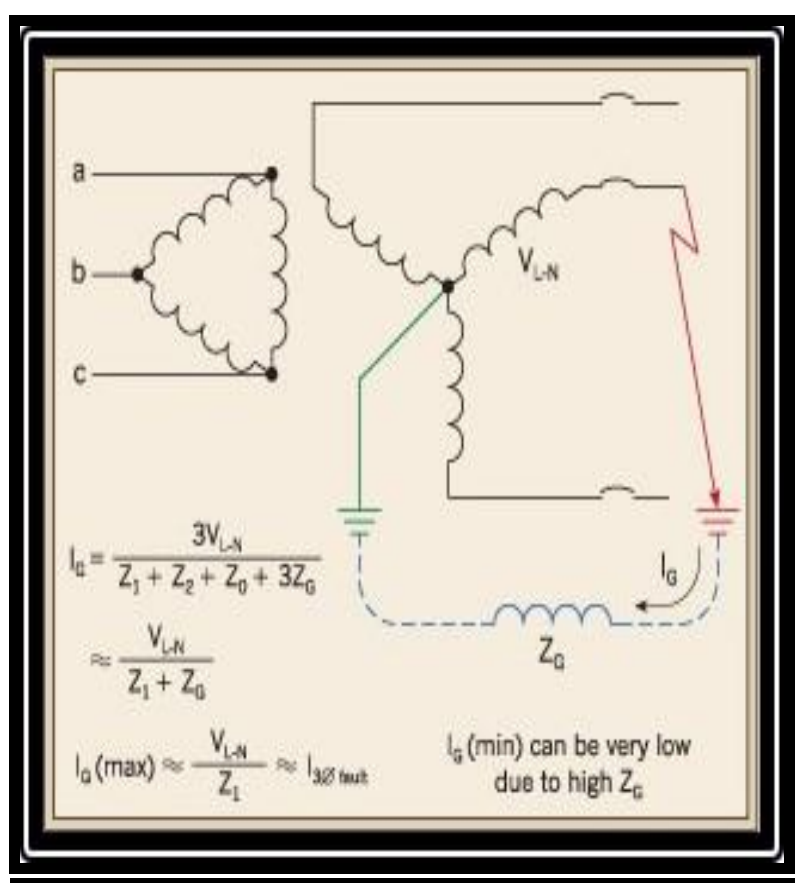

Fig. 6. Single - phase earth fault in 4-wire LV system [11].

Equation (2) expresses the dependence of zero-sequence current on the soil resistivity.

$$
\mathrm{I}_{\mathrm{G}}=3 \mathrm{I}_{0}=3 \mathrm{~V}_{(\mathrm{LN})} \cdot\left(\frac{1}{\mathrm{Z}_{1}+\mathrm{Z}_{2}+\mathrm{Z}_{0}+3 \mathrm{Z}_{\mathrm{G}}}\right)
$$

Where:

$\mathrm{I}_{\mathrm{G}} \quad$ : is the per-unit ground fault;

$\mathrm{I}_{0} \quad$ : is the per-unit zero-sequence current;

$\mathrm{V}_{(\mathrm{LN})}$ : is the per-unit phase voltage;

$\mathrm{Z}_{1} \quad$ is the per-unit positive sequence impedance;

$Z_{2}$ : is the per-unit negative impedance;

$\mathrm{Z}_{0}$ : is the per-unit zero impedance;

$\mathrm{Z}_{\mathrm{G}}$ : is the per-unit soil impedance.

It is important to observe that the main variable in equation (2) is the fault impedance $\left(Z_{G}\right)$, which has a significant impact on the magnitude of the earth fault current $\left(\mathrm{I}_{\mathrm{G}}\right)$. The overwhelming significant part of this impedance is attributed to the ground or soil resistance 
component. The zero-sequence $\left(I_{0}\right)$ fault current is thus influenced by the soil resistivity. Equations (1) and (2) are used to demonstrate the detrimental effects of changing soil resistivity on zero-sequence currents. In this respect, the zero-sequence current is evaluated on the basis of the field measured value of the soil resistivity as well as in terms of $5-10 \%$ increase and decrease of the measured soil resistivity.

\section{Results and Discussion}

The field tests conducted yields the following observations indicated in table II.

Table II. - Field test Results

\begin{tabular}{|c|c|}
\hline Soil Type & Silica/Clay \\
\hline Soil Conditions & Moist \\
\hline Soil Temperature & $15.7^{\circ} \mathrm{C}$ \\
\hline Apparent Resistivity & $488.74 \Omega . \mathrm{m}$ \\
\hline Soil Resistance & $25.5 \Omega$ \\
\hline
\end{tabular}

The tabulated results show that the soil resistivity, at the measurement time and season, has increased beyond the usual limit for clay and sand mixtures (see Table I) type of soil by 62 . $91 \%$. Assuming $Z_{1}=Z_{2}=Z_{0}=0.04$ p.u (transformer impedance) with $\mathrm{Z}_{\mathrm{G}}=25.5 \Omega$ (see Table II), the zero-sequence current magnitude obtained using equation (2) would be $85.716 \mathrm{~A}$. Considering the usual soil resistivity limit value, the zero-sequence current value at the limit point would be $136.923 \mathrm{~A}$, which is $37.40 \%$ increase in the value obtained at measured soil resistivity. For a $5-10 \%$ increase or decrease in the soil resistivity of the measured value, the zero-sequence currents obtained are indicated in figure 7.

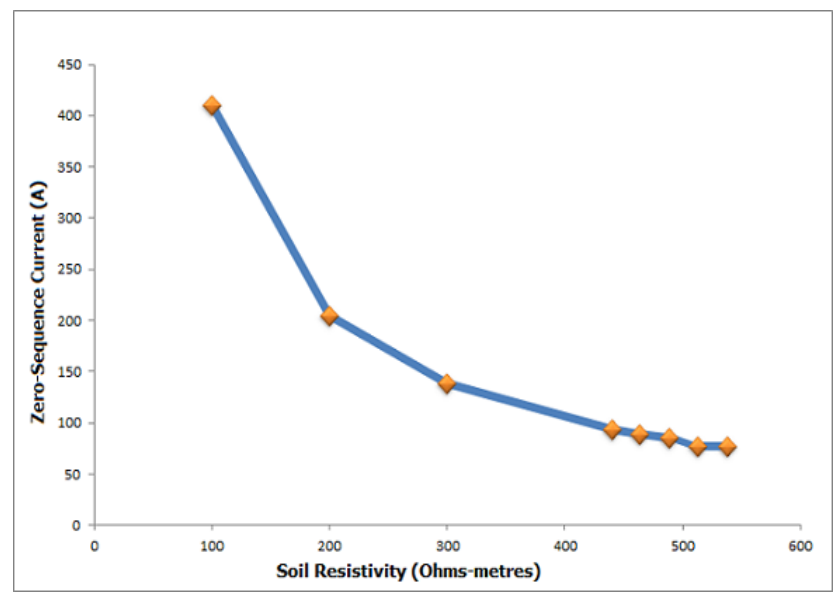

Fig. 7. Zero-Sequence Current versus Soil Resistivity Graph.

The graph obtained shows that for a $(5-10 \%)$ increase in the measured value of the soil resistivity, the zerosequence current experiences further decrease in the value. Yet for a $(5-10 \%)$ decrease in the measured value of the soil resistivity, the fault current increases further. This indicates that higher values of soil resistivity caused by several factors are detrimental to the measurement of the earth fault current as it becomes small in magnitude. It could be shown that beyond the prescribed limit value of the soil resistivity of the type of soil involved in this study, the fault current decay worsens.

\section{Conclusion}

Soil resistivity plays a significant part in the determination of zero-sequence current that may result from earth faults in low voltage distribution systems. However, moisture content and temperature directly impact on the resistivity, and thus indirectly affecting the magnitude of zero-sequence current. The presence of moisture and temperature level is also related to regional geological structure and meteorological conditions. Therefore, as part of risk assessment for rural electrification projects in South Africa, a correlation model between prospective zero-sequence current inherent to variations in the soil conditions should be adopted. In this context, the standard zero sequence fault resistance of $25 \Omega$ as prescribed by the IEEE Std. 1422007 [12] is not always possible to attain, given the ever changing conditions soil conditions.

\section{References}

[1] World development Indicators, "Electricity production, Sources and access", http://www. data.worldbank.org/indicator/EG.ELC.ACCS.ZS, 20012. Last access $1 / 07 / 2016$.

[2] South African National CENSUS, statistical release P0302: "Mid-year population estimates - 2015", pp.7.

[3] SANS 10292 Ed.2 "Earthing of Low-Voltage (LV) Distribution Systems" (2013) Published by SABS Standards Division, ISBN 978-0-626-28761-0, pp 14-17.

[4] IEC 60364-1 Ed.5 "Low-voltage electrical installations.

Part 1: Fundamental principles, assessments of general characteristics, definitions", ISBN 2-8318-8354-7, pp. 23.

[5] IEEE Standard 81 Earth Resistivity, Ground Impedance, and Earth Surface Potentials of a Grounding System", IEEE Power and Energy Society, ISBN 978-0-7381-8028-1.

[6] M. Kizhlo and A. Kanbergs "Research of the Parameter Changes of the Ground System", 978-1-4244-4702-2, 2009 IEEE, pp 2-3.

[7] J. Laver and H. Griffiths, "The Variability of Soils in Earthing Measurements and Earthing System Performance", Rev. Energy. Ren. : Power Engineering (2001), pp 57-61.

[8] S. Diop, F. Stapelberg, K. Tegegn, S. Ngubelanga and L. Heath, "A review on Problem Soils in South Africa", Council for Geoscience Report number: 2011-0062.

[9] Lightning and Surge Technologies, "Earthing Techniques" pp. 5-6.

[10] H. Geldenhuys, G. Stanford, "Earthing of MV and LV Distribution Lines: A multi-faceted problem", Eskom, Industry Association Resource Centre (IARC), pp.1

[11] http://www.askiitians.com/forums/General-Physics/sketcha-graph-showing-variation-of-resistivity-of_85008.htm, Last access $21 / 10 / 2016$.

[12] IEEE Standard 142 ${ }^{\mathrm{TM}}-2007$, “IEEE Recommended Practice for Grounding of Industrial and Commercial Power Systems, Published by the Institute of Electrical and Electronics Engineers, Inc., ISBN 0-7381-5639-2, pp.167. 